\title{
Solvation enthalpy of uranium tetrachloride in aqueous- alcohols mixed solvents
}

\author{
Raghvendu Pathak \\ Department of Chemistry, Pachhunga University College, Aizawl7960oI, Mizoram, India
}

\begin{abstract}
The process of interaction between ions of a solute and the molecules of the solvent through relatively weak covalent bonds is called solvation. It involves evening out a concentration gradient and evenly distributing the solute molecules within the solvent. Hydration is a special case of solvation when the solvent molecules are water. Solvation energy, generally, is the energy released when ions in crystal lattices associate with molecules in a solvent, however it can be positive or negative, depending upon the combined effects of lattice and hydration energies in case of aqueous-ionic solid dissolution. Uranous chloride or uranium tetrachloride $\left(\mathrm{UCl}_{4}\right)$ is a green crystalline solid which sublimes in vacuum at $500^{\circ} \mathrm{C} / 10^{-3} \mathrm{~mm}$. It is a Lewis acid and hence dissolves in solvents which can act as non-protic Lewis bases. Although dissolution of uranium tetrachloride crystals in water is an exothermic process yielding a green solution which is fairly stable in the cold, yet is hydrolyzed to a considerable extent to furnish an acidic reaction. Solvation enthalpies of quadrivalent uranium system have been scantly reported. The present communication deals with the calculation of enthalpy of solution of uranium tetrachloride in aqueous-non-aqueous solvent mixtures, particularly in 10 and 20 weight (wt) \% methyl alcohol-water and ethyl alcohol-water systems at $25^{\circ} \mathrm{C}$ calorimetrically and thereby estimating the solvation enthalpy of $\mathrm{UCl}_{4}$ in the said media.
\end{abstract}

Key words: Ethanol; methanol; exothermic reaction; solvation enthalpy; uranium tetrachloride.

\section{Received 06 June 2017 \\ Accepted o7 August 2017 \\ *For correspondence $\square$ : rppuc41@yahoo.com}

\section{Introduction}

Uranium $\left({ }_{92} \mathrm{U}\right)$ which is one of the heaviest naturally occurring elements and which has six naturally occurring known isotopes ranging from U-233 to U-238 and is weakly radioactive, occurs naturally in varying but small amounts in soil, rocks, water, plants, animals, and in all human beings. In a typical sample of natural uranium, $99.27 \%$ of the mass consists of U-238 atoms, about $0.72 \%$ of the mass consists of U- 235 atoms, and a very small amount of about $0.0055 \%$ by mass is that of U-234. ${ }^{1}$ It is a silvery white metal and is malleable, ductile and slightly paramagnetic.

The heat or enthalpy of solution refers to the enthalpy change associated with the dissolution of a given amount of solute in a large excess volume of solvent at a given temperature and pressure, resulting in infinite dilution. It is generally expressed in $\mathrm{kJ} / \mathrm{mol}$. The enthalpy of solution of an ideal solution, by convention, is 
taken to be naught. For non-ideal solutions of electrolytes it is connected to the activity coefficient of the solute(s) and the temperature derivative of the relative permittivity. On the other hand, solvation is a process of an interaction of a solute with the solvent molecules ${ }^{2}$, leading to stabilization of the solute species in the solution. It involves evening out a concentration gradient and evenly distributing or dispersing the solute within the solvent via host of interactions. The enthalpies of solution, free energies and enthalpies of solvation are of fundamental importance since they constitute the basis of ion-solvent interactions. ${ }^{3}$ For the most part, the Born equation (1) and the Born- Bjerrumequation (2) have dominated many attempts to calculate these quantities. $^{3}$

$$
\begin{aligned}
& \Delta \mathrm{G}_{\text {solv }}=-\frac{\left(\mathrm{ze}^{2}\right)}{2 \mathrm{ri}}\left\{1-\frac{1}{\varepsilon}\right\} \\
& \Delta \mathrm{H}_{\mathrm{solv}}=-\frac{\left(\mathrm{ze}^{2}\right)}{2 \mathrm{ri}}\left\{1-\frac{1}{\varepsilon}-\frac{\mathrm{T} \partial \ln \varepsilon}{\varepsilon \partial \mathrm{T}}\right\}_{\mathrm{P}}
\end{aligned}
$$

where $r_{i}$ is the crystal radii of the cations and anions and $\boldsymbol{\varepsilon}$ is the relative permittivity of the medium. Although various investigators have calculated enthalpy of solution and thereby other thermodynamic properties on that basis adopting various diverse methods, for example, Mark Salomon, in his paper, evaluated the energetics of single-ion solvation in water and propylene carbonate on the basis of electrostatic model. ${ }^{3}$

In this line, measurements of heat of solution of anhydrous uranium tetrachloride in aqueous $\mathrm{HCl}-\mathrm{LiCl}$ mixtures at constant ionic strength were reported by Hearne and White ${ }^{4}$ as early as 1957. Weeda and Somsen, ${ }^{5}$ on the other hand, measured the enthalpies of solution of LiI, NaI, $\mathrm{KF}, \mathrm{KCl}, \mathrm{KBr}, \mathrm{KI}, \mathrm{RbI}$ and $\mathrm{CsI}$ in $\mathrm{N}$ methylacetamide at $35^{\circ}$ with the help of an adiabatic calorimeter and ionic enthalpies of solvation of the alkali metal and halide ions in $\mathrm{N}$ methylformamide and $\mathrm{N}$-methylacetamide were estimated. Solvation enthalpies of various nonelectrolytes in water, propylene carbonate, and dimethyl sulfoxide were reported through the measurement of heats of solution of a number of nonelectrolytes mostly alcohols and hydrocarbons in the solvents like water, propylene carbonate, and dimethyl sulfoxide. ${ }^{6}$ The enthalpy of formation of uranium tetrachloride, $\mathrm{UCl}_{4}(\mathrm{~s})$, in the absence of dissolved oxygen, was determined by Fitzgibbon et al. ${ }^{7}$ from measurements of the enthalpies of solution of uranium metal and of $\mathrm{UCl}_{4}(\mathrm{~s})$ in $4 \mathrm{M}$ and $6 \mathrm{M} \mathrm{HCl}$ containing added $\mathrm{Na}_{2} \mathrm{SiF}_{6}$. The heats of solution of the sodium $\mathrm{n}$-alkyl sulphonates from methyl to octyl were evaluated at $25^{\circ} \mathrm{C}$ in water, $\mathrm{D}_{2} \mathrm{O}$, and three alcohol-rich mixtures with water, all at low solute concentrations so as to avoid solutesolute interaction completely. ${ }^{8}$ Akabori et al. ${ }^{9}$ determined the standard molar enthalpy of formation of $\mathrm{UNCl}$ from the measurement of enthalpy of solution of UNCl(s) and a mixture of $\mathrm{UCl}_{4}$ and $\mathrm{NH}_{4} \mathrm{Cl}$ in a mixture of $\mathrm{HCl}$ and $\mathrm{FeCl}_{3}$ calorimetrically. The enthalpy of solution of trans-cyclohexyl-1,4-diamine and cis-cyclohexyl -1,2-diamine in water was determined calorimetrically. ${ }^{10}$ Sedov et al., ${ }^{11}$ however, reported enthalpy of solvation of low polar solutes in formamide derivatives at $298 \mathrm{~K}$. The heat of hydrolysis of uranium (IV) in perchloric acid solution was measured via spectrophotometric technique. A value of $10.7 \pm 1 \mathrm{kcal}$ per mole was obtained which was in good agreement with a previous value determined by a calorimetric method. The entropy of association of uranium (IV) with hydroxyl ion was found to be +52 e.u..$^{12}$ Previously enthalpies of precipitation of a number of oxinate complexes with divalent ions in aqueous phase have been studied and reported, ${ }^{13}$ however, standard heats of formation of uranyl (II) and thorium (IV) oxinates have been computed by Thakur et al. ${ }^{14}$ in later years. Some work had also been reported on uranium (VI) compounds earlier. ${ }^{15,16}$ More recently thermochemical studies of thorium (IV) and zirconium (IV) tetrabenzoates have been reported by Pathak $^{17}$ but work on solvation enthalpies of quadrivalent uranium system have been very few and far between.

As solvation enthalpies of quadrivalent uranium system have scantly been reported, the 
present paper deals with the calculation of enthalpy of solution of $\mathrm{UCl}_{4}$ solutioncalorimetrically in 10 and 20 weight (wt) \% $\mathrm{MeOH}-\mathrm{H}_{2} \mathrm{O}$ and $\mathrm{EtOH}-\mathrm{H}_{2} \mathrm{O}$ systems at $25^{\circ} \mathrm{C}$ and thereby finding the solvation enthalpies of $\mathrm{UCl}_{4}$ from the heat of solution data. Owing to the dearth of auxiliary thermodynamic data for polyvalent electrolytic system and complexity of the theoretical interpretations, the result have been discussed and can be considered as having mere data value.

\section{Materials and Methods}

Uranium being an active metal dissolves in dilute acids furnishing quadrivalent uranium, $\mathrm{U}$ (IV), which upon oxidation yields hexavalent uranium, U(VI), however, the two most common uranium species in aqueous solution being $\mathrm{U}^{4+}$ and $\mathrm{UO}^{2+} .{ }^{18}$ Uranium (IV) or (U⿱⺌$\left.{ }^{4+}\right)$ ion which has a high charge density and smaller radius of $0.97 \AA$ or 97 picometre $(\mathrm{pm})$, comparable to that of $\mathrm{Na}^{+}$ ion $(0.95 \AA)$, has a strong polarizing power and in aqueous solution it hydrolyses as

$\mathrm{U}^{4+}+\mathrm{H}_{2} \mathrm{O} \rightarrow \mathrm{U}(\mathrm{OH})_{3}{ }^{3+}+\mathrm{H}^{+}$.

$\mathrm{U}^{4+}$ ions form stronger complexes with a given ligand. In presence of air or oxygen this aqueous solution turns yellow from green due to the formation of $\mathrm{UO}^{2+}$ ions. ${ }^{19-21}$ The aforementioned reaction sans air does not take place. $\mathrm{UCl}_{4}$ and its addition compounds are highly susceptible to hydrolysis and oxidation, consequently all manipulations were done in an atmosphere of dry nitrogen $\left(\mathrm{N}_{2}\right)$, devoid air and moisture completely. For this commercial nitrogen was purified by passing it successively through a tube containing Cu-turnings at $300-350^{\circ} \mathrm{C}$ to remove oxygen and then through tubes containing $\mathrm{CaCl}_{2}$ $+\mathrm{P}_{2} \mathrm{O}_{5}$ and silica-gel to remove even traces of moisture.

Reagents of analytical grade were utilized for the preparation of crystalline compounds. $\mathrm{UCl}_{4}$ was prepared by the action of hexachloropropene $\left(\mathrm{Cl}_{3} \mathrm{C}-\mathrm{ClC}=\mathrm{CCl}_{2}\right.$ or $\left.\mathrm{HCP}\right)$ on uranium trioxide $\left(\mathrm{U}_{3} \mathrm{O}_{8}\right)^{22} 20 \mathrm{gm}$ of uranium trioxide was first dried at $110^{\circ} \mathrm{C}$ for several hours and then mixed with HCP $(90 \mathrm{ml})$ and the mixture was heated in dry nitrogen-gas atmosphere. Since the reaction was brisk and highly exothermic in the beginning, it was necessary to cool the reaction mixture. When the reaction had subsided, the red coloured mixture was boiled under reflux for six hours, at the end of which the colour changed from red to green. The mixture was allowed to cool under nitrogen and the product was filtered. The residue containing $\mathrm{UCl}_{4}$ was then washed several times with anhydrous carbon tetrachloride $\left(\mathrm{CCl}_{4}\right)$ to drive out the soluble impurities. The green crystalline $\mathrm{UCl}_{4}$ so obtained was heated on a steam bath to remove $\mathrm{CCl}_{4}$, if any. The crude sample of anhydrous $\mathrm{UCl}_{4}(25 \mathrm{~g}$; $90 \%$ ) obtained as a green powder was stored under dry $\mathrm{N}_{2}$ gas atmosphere. It was then purified through vacuum sublimation in a pyrex glass tube under the reduced pressure of $500^{\circ} \mathrm{C} / 10^{-3}$ $\mathrm{mm}$. The obtained $\mathrm{UCl}_{4}$ solid was then analyzed for uranium and chlorine by the oxinate and silver chloride methods respectively ${ }^{23}$ (Found: U, $62.5 \% ; \mathrm{Cl}, 37.0 \%$; Calc. for $\mathrm{UCl}_{4}: \mathrm{U}, 62.7 \% ; \mathrm{Cl}$, $37.3 \%$ ).

Reagent grade HCP was distilled from phosphorus pentoxide $\left(\mathrm{P}_{2} \mathrm{O}_{5}\right)$ and middle fraction having boiling point (b.p.) $214^{\circ} \mathrm{C}$ was collected for use. Conductivity water was always used. Triply distilled ordinary distilled water with alkaline potassium permanganate $\left(\mathrm{KMnO}_{4}\right)$ collected in an all glass 'pyrex' glass receiver was used in all solvent mixtures.

\section{Results}

Results have been calibrated in Tables 1 to 4 which represent the enthalpies of solution of $\mathrm{UCl}_{4}$ in 10 and $20 \mathrm{wt}$. \% methanol-water systems and 10 and 20 wt. \% ethanol-water systems respectively in complete absence of air under a dry nitrogen atmosphere to avoid oxidation and hydrolysis. In each case the compound dissolved instantaneously furnishing clear green solution which on protracted standing of about 24 hours in air exhibited the presence of a suspended colloidal precipitate which Young ${ }^{24}$ identified it to be a hydrous oxide of U(VI). The heat of solution in aqueous $\mathrm{HCl}$ ( 1 mole of $\mathrm{HCl}$ per 8.808 moles of water had been found to be $39.4 \pm 0.2 \mathrm{kcal} \mathrm{mole}^{-1}$ $\left(=164.85 \pm 8.4 \mathrm{~kJ} \mathrm{~mole}^{1}\right)^{25}$ which compares well 
Table 1 | Enthalpy of solution of $\mathrm{UCl}_{4}$ crystal in $10 \mathrm{wt} \%$ $\mathrm{MeOH}-\mathrm{H}_{2} \mathrm{O}$ mixture at $25^{\circ} \mathrm{C}$.

Molar mass of $\mathrm{UCl}_{4}=379.83 \mathrm{~g} \mathrm{~mol}^{-1}$

\begin{tabular}{cccc}
\hline $\mathrm{UCl}_{4}(\mathrm{c})$ & & $\Delta \mathrm{H}$ & $\Delta_{\text {soln }}$ \\
\hline $\mathrm{mg}$ & $\mathrm{m}$ mole & $\mathrm{J}$ & $\mathrm{kJ} \mathrm{mol}^{-1}$ \\
\hline 125.3 & 0.3298 & 84.2 & -255.3 \\
132.8 & 0.3496 & 90.3 & -258.5 \\
141.7 & 0.3730 & 96.0 & -257.4 \\
151.6 & 0.3991 & 101.7 & -254.8 \\
159.4 & 0.4196 & 107.5 & -256.2 \\
\hline
\end{tabular}

Mean $\Delta_{\text {soln }} \mathrm{H}=-256.4 \pm 1.36 \mathrm{~kJ} \mathrm{~mol}^{-1}$

Table 3 | Enthalpy of solution of $\mathrm{UCl}_{4}$ crystal in $10 \mathrm{wt} \%$ EtOH- $\mathrm{H}_{2} \mathrm{O}$ mixture at $25^{\circ} \mathrm{C}$.

\begin{tabular}{cccc}
\hline $\mathrm{UCl}_{4}(\mathrm{c})$ & & $\Delta \mathrm{H}$ & $\Delta$ soln \\
\hline $\mathrm{mg}$ & $\mathrm{m}$ mole & $\mathrm{J}$ & $\mathrm{kJ} \mathrm{mol}^{-1}$ \\
\hline 91.3 & 0.2404 & 59.7 & -248.6 \\
121.4 & 0.3196 & 78.5 & -245.8 \\
136.2 & 0.3586 & 88.6 & -247.2 \\
141.7 & 0.3730 & 93.0 & -249.4 \\
145.2 & 0.3822 & 93.9 & -245.7 \\
\hline
\end{tabular}

Mean $\Delta_{\text {soln }} \mathrm{H}=-247.3 \pm 1.48 \mathrm{~kJ} \mathrm{~mol}^{-1}$

Table 5 | Solvation enthalpies of $\mathrm{UCl}_{4}$ in aqueous-nonaqueous solvent mixture in $\mathrm{kJ} \mathrm{mol}^{-1}$.

\begin{tabular}{ccccc}
\hline 10 wt. \% & \multicolumn{3}{c}{20 wt. \% } \\
\hline Solvent & $-\Delta_{\text {soln }} \mathrm{H}$ & $-\Delta_{\text {solv }}$ & $-\Delta_{\text {soln }}$ & $-\Delta_{\text {solv }}$ \\
\hline $\mathrm{MeOH}-\mathrm{H}_{2} \mathrm{O}$ & 256.4 & 7833.9 & 274.5 & 7852.0 \\
$\mathrm{EtOH}-\mathrm{H}_{2} \mathrm{O}$ & 247.3 & 7824.8 & 266.8 & 7844.3 \\
\hline
\end{tabular}

with the calculated values in tables 1 to 4 considering the fact that those have been calculated in 10 and $20 \mathrm{wt} . \%$ methanol-water systems and 10 and $20 \mathrm{wt}$. \% ethanol-water mixtures.

\section{Discussion}

From the tables we find that the heats of solution data do not obey Debye-Huckel theory and the effects of concentration on the enthalpy of solution are not observed. Since the solution possesses very low concentration of the solute, it is presumed that the mean enthalpy of solution $\Delta \mathrm{H}_{\mathrm{S}}$ values are at infinite dilution $\left(\Delta_{\text {soln }} \mathrm{H}^{\circ}\right.$ or $\Delta_{\mathrm{s}} \mathrm{H}^{\circ}$ ). The enthalpies of solution when com-
Table 2 | Enthalpy of solution of $\mathrm{UCl}_{4}$ crystal in $20 \mathrm{wt} \%$ $\mathrm{MeOH}-\mathrm{H}_{2} \mathrm{O}$ mixture at $25^{\circ} \mathrm{C}$.

\begin{tabular}{cccc}
\hline $\mathrm{UCl}_{4}(\mathrm{c})$ & & $\Delta \mathrm{H}$ & $\Delta_{\text {soln }}$ \\
\hline $\mathrm{mg}$ & $\mathrm{m}$ mole & $\mathrm{J}$ & $\mathrm{kJ} \mathrm{mol}^{-1}$ \\
\hline 81.2 & 0.2138 & 58.3 & -272.8 \\
101.4 & 0.2669 & 73.4 & -275.2 \\
109.8 & 0.2891 & 79.4 & -274.9 \\
119.7 & 0.3151 & 86.2 & -273.6 \\
137.4 & 0.3617 & 99.8 & -276.1 \\
\hline
\end{tabular}

Mean $\Delta_{\text {soln }} \mathrm{H}=-274.5 \pm 1.17 \mathrm{~kJ} \mathrm{~mol}^{-1}$

Table 4 | Enthalpy of solution of $\mathrm{UCl}_{4}$ crystal in $20 \mathrm{wt} \%$ etOH- $\mathrm{H}_{2} \mathrm{O}$ mixture at $25^{\circ} \mathrm{C}$.

\begin{tabular}{cccc}
\hline $\mathrm{UCl}_{4}(\mathrm{c})$ & & $\Delta \mathrm{H}$ & $\Delta_{\text {soln }}$ \\
\hline $\mathrm{mg}$ & $\mathrm{m} \mathrm{mole}$ & $\mathrm{J}$ & $\mathrm{kJ} \mathrm{mol}^{-1}$ \\
\hline 71.4 & 0.1879 & 49.9 & -265.9 \\
73.3 & 0.1929 & 51.8 & -268.5 \\
75.4 & 0.1985 & 52.9 & -266.7 \\
76.5 & 0.2014 & 53.9 & -267.8 \\
77.2 & 0.2032 & 53.7 & -264.6 \\
\hline
\end{tabular}

bined with the crystal energy of the $\mathrm{UCl}_{4}$ give values for the solvation enthalpies of $\mathrm{U}^{4+}$ (solv) and the $\mathrm{Cl}$ (solv). The lattice energy $\left(\mathrm{U}_{\mathrm{I}}\right)$ of $\mathrm{UCl}_{4}$ (c) has been calculated from Kapustinskii equation (3)

$$
U_{L}=K \cdot \frac{v \cdot\left|z^{+}\right| \cdot\left|z^{-}\right|}{r^{+}+r^{-}} \cdot\left(1-\frac{d}{r^{+}+r^{-}}\right)
$$

where $\mathrm{K}=1.2025 \times 10^{-4} \mathrm{~J} \mathrm{~m} \mathrm{~mol}^{-1}, d=3.45 \times 10^{-11}$ $\mathrm{m}, \mathrm{v}=$ the number of ions in the empirical formula, $r^{+}$and $r=$ radii of the cation and anion respectively, and $z^{+}$and $z^{-}$are the numbers of elementary charge on the cation and anion respectively, ${ }^{26}$ taking ionic radii of $\mathrm{U}^{4+}$ and $\mathrm{Cl}^{-}$ions as $97 \mathrm{pm}$ and $181 \mathrm{pm}$ respectively. The calculated value comes out to be $-7577.5 \mathrm{~kJ} \mathrm{~mol}^{-1}$. However, the theoretical value of lattice energy of $\mathrm{UCl}_{4}$ (c) taking the same value of $\mathrm{U}^{4+}$ and $\mathrm{Cl}^{-}$ radiis found to be $-7449.9 \mathrm{~kJ} \mathrm{~mol}^{-1} .{ }^{27}$ The difference between the two values happens to be $127.6 \mathrm{~kJ} \mathrm{~mol}^{-1}$, which is less than even $2 \%$. Table 5 lists the solvation enthalpy values of $\mathrm{UCl}_{4}$ in different solvent mixtures which has been calculated by applying the formulae, 
$\Delta_{\text {solvn }} \mathrm{H}=\mathrm{U}_{\mathrm{L}}+\Delta_{\text {soln }} \mathrm{H}$

where $\mathrm{U}_{\mathrm{I}, \mathrm{S}} \mathrm{s}$ the lattice energy of $\mathrm{UCl}_{4}$ (c). It can be observed that the solvation enthalpies in different solvents are higher for $20 \mathrm{wt}$ \% mixture than that for $10 \mathrm{wt}$. \% mixture and they decrease in the order $\mathrm{MeOH}-\mathrm{H}_{2} \mathrm{O}>\mathrm{EtOH}-\mathrm{H}_{2} \mathrm{O}$. This can partially be explained based on steric phenomenon. As methyl alcohol is less bulky it will be accommodated around the small $\mathrm{U}^{4+}$ ion more favourably and conveniently than the ethyl alcohol.

Harned and Owen $^{28}$ have noticed that the interpretation of enthalpy of transfer of polyvalent electrolytes is rather complex and a number of interactions, mainly electrostatic and quantum mechanical play vital roles. However, it is for sure that from the enthalpies of solution data in aqueous and non-aqueous media, a host of thermodynamic properties, viz. enthalpy of solvation, enthalpy of vaporization, enthalpy of hydration, enthalpy of transfer, etc. can be calculated and results can be interpreted in various fruitful and tangible ways. In fact, Gill et al. ${ }^{29}$ have calculated $\Delta C_{p}$ values, partial molar heat capacities for the solutes at infinite dilution, and even minimum solubility temperatures from the results of such data. Moreover, enthalpies of solvation data have been generously utilized by host workers to estimate the enthalpy due to solute-solvent interactions and for host of other thermodynamic purposes including the calculation of enthalpy for the formation of a cavity in a solvent using scaled particle theory (SPT).$^{30}$ From the tables 1-4, enthalpy of solvation of $\mathrm{UCl}_{4}$ in 10 and $20 \mathrm{wt} \%$ in $\mathrm{MeOH}-\mathrm{H}_{2} \mathrm{O}$ and $\mathrm{EtOH}-\mathrm{H}_{2} \mathrm{O}$ mixtures has been calculated. Data of this type are very few and far between and therefore we reserve our discussion until more data are gathered in future.

The negative values of solvation enthalpies of $\mathrm{UCl}_{4}(\mathrm{c})$ in10 wt. and $20 \mathrm{wt}$ \% methanol-water systems and 10 and $20 \mathrm{wt}$ \% ethanol-water systems respectively clearly show the exothermicity of the reaction when $\mathrm{UCl}_{4}$ (c) is dissolved in these mixture systems. Data of these types are very few and far between, and the present discussion would go a long way in stimulating research in the said field.

\section{References}

I. U.S. Department of Energy Office of Environmental Management Depleted Uranium Hexafluoride Management Program Depleted Uranium Hexafluoride, Fact Sheet I,200I.

2. IUPAC, Compendium of Chemical Terminology, and ed. Compiled by McNaught AD, \& WilkinsonA, Blackwell Scientific Publications, Oxford; 1997.XML on-line corrected version: http://goldbook.iupac.org. (2006), created by Nic, M. Jirat,J. \& Kosata, B. updates compiled by Jenkins, $A$.

3. Salomon, M. (1970). Thermodynamics of ion solvation in water and propylene carbonate. Journal of Physical Chemistry 74 (12), 2519-2524.

4. Hearne, J. A. \& White, A. G. (1957). The heat of solution of uranium tetrachloride and the hydrolysis of the uranium (IV) ion. Journal of the Chemical Society 1957 , 208I-2085.

5. Weeda, L. \& Somsen, G. (1967). Enthalpies of solvation of alkali metal and halide ions in $N$-methylformamide and $N$-methylacetamide at $25^{\circ}$. Recueil des Travaux Chimiques des Pays-Bas 86 (3), 263-274.

6. Krishnan, C. V. \& Friedman, H. L. (1969). Solvation enthalpies of various nonelectrolytes in water, propylene carbonate, and dimethyl sulfoxide. The Journal of Physical Chemistry 73 (5), 1572-1580.

7. Fitzgibbon, G. C., Pavone, D. \& Holley, C. E. (I97I). Enthalpy of formation of uranium tetrachloride. The Journal of Chemical Thermodynamics 3 (I), I5I-I62.

8. Krishnan, C. V. \& Friedman, H. L. (1973). Enthalpies of alkyl sulfonates in water, heavy water, and wateralcohol mixtures and the interaction of water with methylene groups. Journal of Solution Chemistry 2 (I), 37-5I.

9. Akabori, M., Kobayashi, F. Hayashi, H. Ogawa, T. Huntelaar, M. E., Booij A. S. \& vanVlaanderen, P. (2002). The standard molar enthalpy of formation of UNCl. The Journal of Chemical Thermodynamics 34, I46I- 66 .

Io. Tomé, L. I. N., Jesus, A. J. L., Esteves de Castro, R. A., Teixeira, M. H. S. F., Canotilho, J. \& Eusébio, M. E. S. (2007). Solvation enthalpy and the thermodynamics of hydration of trans-cyclohexyl-I,4-diamine and ciscyclohexyl-1,2-diamine. The Journal of Chemical Ther- 
modynamics 39 (I0), 1357- 62.

II. Sedov, I. A., Magsumov, T. I., Stolov, M. A. \& Solomonov, B. N. (2016). Standard molar Gibbs free energy and enthalpy of solvation of low polar solutes in formamide derivatives at $298 \mathrm{~K}$. Thermochimica Acta 623, 9I4.

I2. Betts, R. H. (1955). Heat of hydrolysis of uranium (IV) in perchloric acid solutions. Canadian Journal of Chemistry 33 (12), 1775-79.

13. Jonassen, H. B. \& Oliver, J. R. (1958). Metallated dye complexes iv, the stereochemistry of copper (II)--dye complexes. Journal of the American Chemical Society 80 (го), 2347.

I4. Thakur, S. Kumar, A. \& Pathak, R. (1995). Standard heats of formation of uranyl (II) and thorium (IV) oxinates. Journal of Indian Chemical Society 72, 823-24.

15. Chernyaev, I. I. (1966). Complex Compounds of Uranium. Jerusalem Israel:Programme for Scientific Translation., pp. 1520.

16. Thakur, L. Thakur, S. Pathak, M. \& Jha, R. N. (1992). Thermochemical studies of diaquodipropionatodioxouranium (VI). Journal of Indian Council of Chemists VIII (I), 25-26.

17. Pathak, R. (2016). Thermochemical studies of thorium (IV) and zirconium (IV) tetrabenzoates. Science Vision I6 (I), IO-I5.

I8. Katz, J. J. \& Seaborg, G. T. (1957). The Chemistry of the Actinide Elements. Methuen \& Co. Ltd, London, pp I508.

19. Katz, J. J. \& Rabinowitch, E. (1951). The Chemistry of Uranium. McGraw-Hill, Reprinted 196I by Dover Publications, New York, pp I-626.

20. Bagnall, K. W. (1972). Lanthanides and Actinides Series One, Volume 7, Butterworths: University Park Press, London, pp. I-367.
2I. Cordfunke, E. H. P. (1969). The Chemistry of Uranium. Elsevier, Amsterdam, pp. I-250.

22. Hermann, J. A., Suttle, J. F. \& Hoekstra, H. R. (1957). Uranium(IV) Chloride. In: Inorganic Syntheses, Volume 5 (ed T. Moeller), John Wiley \& Sons, Inc., Hoboken, NJ, USA, pp. I43-I45.

23. Vogel, A. I. (1955). A Text Book of Quantitative Inorganic Analysis, Theory and Practice. Longmans Green and Co., London, pp. I-9I8.

24. Young, R. C. (1958). Investigation of the black solid formed on reaction of uranium metal with hydrochloric acid. Journal of Inorganic ES Nuclear Chemistry 7(4), 4I8-420.

25. Katz, J. J. \& Rabinowitch, E. (1951). The Chemistry of Uranium (Part I, The Element, Its Binary and Related Compounds. McGraw Hill, pp. I-6o9.

26. Kapustinskii, A. F. (1956). Lattice energy of ionic crystals. Quarterly Reviews, Chemical Society, Io (3), 283294.

27. Lattice Energy Calculator, School of Chemistry, Faculty of Science, The University of Sydney, Australia. https:// scilearn.sydney.edu.au/fychemistry/calculators/ lattice_energy.shtml, (Accessed on 06.06.2017).

28. Harned, H. S. \& Owen, B. B. (1958). The Physical Chemistry of Electrolytic Solutions. $3^{\text {rd }}$ ed. Reinhold Publishing Corporation, NewYork, pp. I-803.

29. Gill, S. J. Nichols, N. F. \& Wadsö, I. (1976). Calorimetric determination of enthalpies of solution of slightly soluble liquids II. Enthalpy of solution of some hydrocarbons in water and their use in establishing the temperature dependence of their solubilities. The Journal of Chemical Thermodynamics 8 (5), 445-452.

3o. Jesus, A. J. L., Eusebio, M. E., Redinha, J. S. \& Leitao, M. L. P. (2000). Enthalpy of solvation of butane diols in different solvents. Thermochimica Acta 344, 38. 